\title{
Dynamic Models of the Creative Industries' Behaviour
}

\author{
Mária Kozáková ${ }^{1, *}$, Kristína Krúpová ${ }^{2}$ \\ ${ }^{1}$ University of Economics, Faculty of Business Management, Department of Business Economy, \\ Dolnozemská cesta 1, 85235 Bratislava, Slovakia \\ ${ }^{2}$ University of Economics, Faculty of International Relations, Department of International Political \\ Relations, Dolnozemská cesta 1, 85235 Bratislava, Slovakia
}

\begin{abstract}
The aim of the paper is to analyse the models describing the development of the Creative Industries in Slovakia. Creative industries are described as the industrial components of the economy in which creativity is an input and content or intellectual property is the output. The creative industries have therefore appeared to be newly represented as a significant and rapidly growing set of industries; an important sector, in other words, for policy consideration. Based on the following findings, we can conclude that the second model is precisely predicting the relationship between the growth in the creative industries and in the aggregate economy in Slovakia. With improved cultural statistics, also a more developed and theoretically better founded analysis would be possible. We therefore see our article primarily as a much-needed step towards developing statistical tools in empirical cultural policy on a consistent basis.
\end{abstract}

\section{Introduction}

According to the literature preview, there is a lack of models explaining the economic value and impact of the creative industries. Indeed, in times of financial and economic crisis, these industries become even more attractive as a source of potential employment and entrepreneurial endeavour. Output and value added, and clearly the main instrument of economic measurement for production is GDP. The contribution of culture to this global measure, i.e., the value added of culture industries, is therefore the main economic indicator often mentioned by the various authors [1-3].

In static models, the time factor is not explicitly taken into account. However, such models are best adapted for the solution of certain tasks. For example, in order to conduct a statics analysis, it is necessary to lay the foundation for the dynamic analysis [4,5]. A static state is such state to which the principles of statics are applicable. Static state is not the state of a "timeless" nature, and the static economy is not the "timeless" economy, but it will be an economy in which there is no "temporary order".

Static models possess property of zero lags. The last means that the value of the output parameter of a static model of $t$ represents at any moment a certain function of value

\footnotetext{
* Corresponding author: maria.kozakova@euba.sk
} 
of its output parameter in the same time point of $t$ and does not depend on values of input parameter to $t$ time point. Static models are set in the form of one-dimensional and multidimensional algebraic functions. The models which are directly considering time factor are usually called dynamic. In such models all variables of economic processes and systems are functions of time. Examples of dynamic models are equilibrium processes by Walras and the interaction of supply and demand by Marshall. Economic systems possess property of a lag effect [6,7]. This property of system is characterized by the speed of change of its output parameters in response to changes of its input parameters and parameters of its functioning, average time of receiving a result when modifying functioning parameters.

We start by describing the two possible fundamental relations between the creative industries and the rest of the economy. We interpret the relation of each model to different theoretical associations, what we should expect to observe if each model were true, and the appropriate policy framework in each case. Using various mapping documents, we then undertake an initial consideration of a set of data samples connected to the two models. However, this paper does not attempt a complete analysis. For that, a much more rigorous approach to modelling, data and statistical analysis would be required. What we aim to provide here is only a theory of the classes of models involved and an illustration of how different sorts of data might be applied to them. This seems to us a necessary first step (prior to a more rigorous approach) in developing the economics of the creative industries $[8,9]$.

This is a useful starting point because it allows us to focus attention on the relational nature of processes of value allocation and cultural validation: cultural value does not operate and is not generated in a social, cultural and political vacuum, but is in fact shaped by the power relations predominant at any one time, and is a site for struggles over meaning, representation and recognition $[10,11]$.

\section{Methods}

The chapter provides the information about research aim, the precise description of the research object and the methodology used in this paper.

\subsection{Research Aim}

The aim of the paper is to propose two dynamic models describing the behaviour represented by development and growth of the Creative Industries in Slovakia. The following research questions were articulated:

- Research question no. 1: What is the dynamic relation between the creative industries' prosperity and the prosperity created by the rest of the Slovak economy?

- Research question no. 2: What is the dynamic relation between the creative industries' growth and the rest of the Slovak economy growth?

\subsection{Object of the Research}

Sectors of the creative industries are formed by the business activities based on individual creativity, skill and talent. They are also the ones that have the potential for capital formation and job creation through the use of intellectual property. The sectors as advertising, architecture, art, antique shops, computer and video games, crafts, design, fashion design, film and video, music, performing arts, publishing, software, broadcasting 
channels and radio belong to the Creative Industries. These areas are mainly related to the high added value and significant impact on the quality of people's lives.

The notion of creative industry implies a number of areas (mainly the art of science and, last but not least, culture) and at the same time it affects the social demand for a change in the perception of the concept of industry, which is still understood only in terms of pure production characteristics. In this context, industry must be seen as an exploitation chain that is already created by creating the conditions for creative activity then includes creative activity, production, reproduction, presentation, representation, including export, storage, archiving and recovery.

\subsection{Methodology}

The economic value of the whole economy in Slovakia is defined as $\mathrm{Y}$, and the economic value of the creative industries as CI.

In the first model (so called welfare model), the creative industries are hypothesized to have a net negative impact on the economy, such that they consume more resources than they produce. A dynamically equivalent statement is that the rate of total factor productivity (TFPCI) growth is less in the creative industries than in other sectors (TFPY). In this model, the creative industries are essentially a 'merit good' sector that produces cultural commodities that are welfare enhancing $(d \mathrm{U} / d \mathrm{CI}>0)$, but that are only economically viable with a transfer of resources from the rest of the economy $(d \mathrm{Y} / d \mathrm{CI}<0)$.

The model is described by the two following formulas:

$$
\begin{aligned}
& (d \mathrm{U} / d \mathrm{CI})>0 \\
& (d \mathrm{Y} / d \mathrm{CI})<0
\end{aligned}
$$

In first model, the creative industries are a net drain on the economy, although a net drain worth having, as the overall effect is welfare positive. This is due to the production of commodities of high cultural value $(d \mathrm{U} / d \mathrm{CI}>0)$ but low market value $(d \mathrm{Y} / d \mathrm{CI})<0)$, as production is inherently unprofitable because demand curves lies everywhere below cost curves. The economic justification for such restitution must ultimately then rest on a market failure argument, with policy appropriately calibrated to estimates of this nonmarket value.

Specifically, it means that growth in the creative industries comes at the cost of aggregate economic growth, as their growth is not what 'the market' wants but must be compelled to support it through transfers. Evidence for first model may therefore accrue in several ways. These include: high levels and rates of negative profit among creative industries firms; low total factor productivity (TFPCI < TFPY); persistently lower income to factors of production in creative industries compared to other industries; and other indications that the economic viability of activities organizations within the creative industries is critically dependent upon resource transfers from the rest of the economy to maintain prices, demand or supply.

If first model is true, we would expect to observe not just an economically stagnant or lowgrowth sector, but also one with lower performance levels (e.g. return on investment, incomes, etc). Such decomposition allows multiple opportunities for empirical assessment. This is an interesting empirical question to re-ask, for the implicit truth of first model is almost axiomatic in the field of cultural economics where few disputes the implicit assumption of below-average income or productivity growth.

Our starting axiom is that change in CI affects GDP (Y) in some way $(\Delta \mathrm{CI} \leftrightarrow \Delta \mathrm{Y})$. The two models proposed are the set of possible dynamic interrelations in which a change in CI activity has either: a negative (first model) or positive (second model) effect on the economy. This is plainly simplistic, yet we suggest it offers a useful starting point to orient 
both empirical analysis and policy discussion in order to be clear and explicit about this hypothesized relation and its evidential support.

For analytic convenience, we also assume that $d \mathrm{CI} / d \mathrm{Y}=0$, meaning that economic growth affects the creative industries no differently to other industries, or technically that income elasticity is unitary. We strongly suspect this not to be the case, but rather that growth in income disproportionately effects demand for the output of the creative industries, but we shall set that aside here. Policy is analysed in terms of whether change in the creative industries changes aggregate utility welfare (or utility, $\mathrm{U}$ ). Again, we presume $d \mathrm{U} / d \mathrm{CI}$ can increase, decrease or leave utility unaffected.

The second model explicitly proposes a positive economic relation between growth in the creative industries and growth in the aggregate economy, such that $d \mathrm{Y} / d \mathrm{CI}>0$. In this model the creative industries are a growth 'driver' in the same way that agriculture was in the early 20th century, elaborately transformed manufacturing was in the $1950 \mathrm{~s}-60 \mathrm{~s}$, and Information and Communication Technology was through the 1980s-90s. There are many possible explanations, but all are some variation upon either the notion that the creative industries introduce novel ideas into the economy that then percolate to other sectors (e.g. design-led innovation), or that the creative industries facilitate the adoption and retention of new ideas or technologies in other sectors.

Involvement of the creative industries in the growth of the economy can occur in two principle ways: supply-side and demand-side. The supply-side interpretation of this model emphasizes the export of new ideas from CI to Y. The demand side interpretation emphasizes how growth in Y causes a proportionate increase in demand for CI services. In practice, it is extremely difficult to separate these two forces without recourse to advanced micro-econometric techniques, which are not attempted here due to data limitations. This model may therefore be true, but with different policy implications depending upon whether causality runs predominantly from CI to Y - the supply-side growth driver model or from Y to $\mathrm{CI}$ - the demand side induction model.

The second model is described by the two following formulas:

$$
\begin{aligned}
& (d \mathrm{Y} / d \mathrm{CI})>0 \\
& (d \mathrm{U} / d \mathrm{CI}) \geq 0
\end{aligned}
$$

If the second model is true, then there is a clear economic case for redirecting resources, not just for the benefit of the creative industries per se, but for the benefit of all. The creative industries, in this view, are clear winners to be backed. Evidence for this model would come from association of the creative industries with growth. This would accrue not just in jobs and commodities, but in new types of jobs and new sorts of commodities and services. The second model proposes the creative industries as growth drivers not because of operational expenditure multipliers, but due to their role in the adoption, retention and absorption of new ideas and technologies.

\section{Results and Discussion}

The creative industries would be therefore considered to create new industries and market niches and to sustain and strengthen extant industries. And specifically, without such advanced investment, aggregate economic growth would suffer. This is the contrary of model 1, in which economic growth suffers when there is such continued investment. Model 2 then argues that the creative industries are good for the economy because they introduce and process the new ideas that drive economic growth. 
Figure 1 shows the development of the GDP as the main indicator of the economic growth in Slovakia. In 2014, GDP growth was $2.4 \%$ and in 2015 and 2016 Slovakia's economy grew $3.6 \%$ and $3.3 \%$ respectively. The highest GDP was reached in 2019.

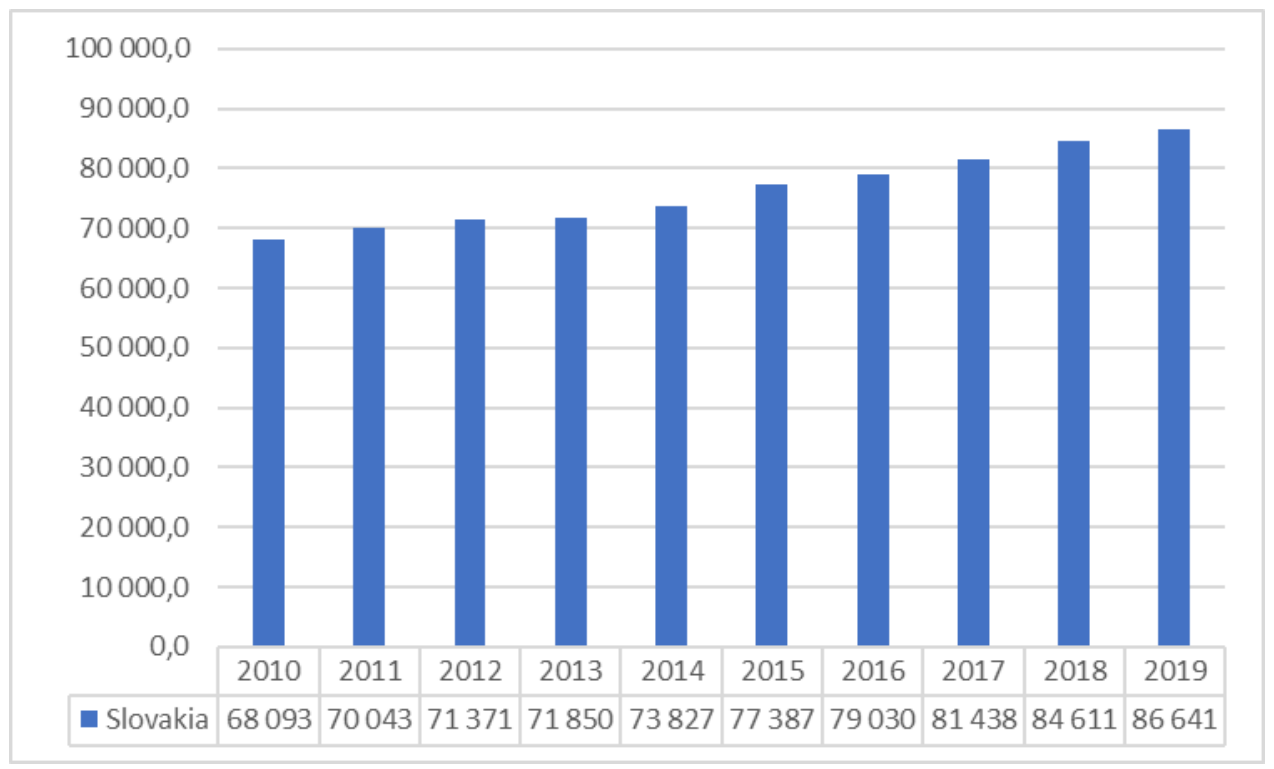

Fig. 1. GDP of Slovakia in chain linked volumes (2010), million euro

Table 1 contains the results of our analysis and data modelling $[12,13]$. The first model related to the welfare, the creative industries are essentially a 'merit good' sector that produces cultural commodities that are welfare enhancing $(d \mathrm{U} / d \mathrm{CI}>0)$, but that are only economically viable with a transfer of resources from the rest of the economy $(d \mathrm{Y} / d \mathrm{CI}<0$ ). The first model is not valid in Slovakia. With improved and continual cultural statistics, also a more developed analysis would be possible.

Tab. 1. The comparison of the model 1 and the model 2

\begin{tabular}{|c|c|c|c|c|c|}
\hline Year & $\mathbf{Y}$ & $\mathbf{U}$ & CI & $d \mathrm{Y} / d \mathrm{CI}$ & $d \mathrm{U} / d \mathrm{CI}$ \\
\hline 2010 & 68093,0 & 418,3 & 9777 & 0,0005127 & 0,031982942 \\
\hline 2011 & 70043,4 & 433,3 & 10246 & 0,0007531 & $-0,119220056$ \\
\hline 2012 & 71371,3 & 476,1 & 9887 & uncountable & uncountable \\
\hline 2013 & 71850,1 & 469,2 & unavailable & uncountable & uncountable \\
\hline 2014 & 73827,8 & 457,4 & unavailable & uncountable & uncountable \\
\hline 2015 & 77387,7 & 452,6 & 11690 & 0,0006086 & $-0,013011152$ \\
\hline 2016 & 79030,9 & 438,6 & 12766 & 0,0004154 & 0,072202591 \\
\hline 2017 & 81438,4 & 499,9 & 13615 & 0,0003151 & uncountable \\
\hline 2018 & 84611,9 & unavailable & 13789 & 0,0004928 & uncountable \\
\hline 2019 & 86641,3 & unavailable & 14115 & 0,023303 & uncountable \\
\hline
\end{tabular}

The second model is based on the premise that $(d \mathrm{Y} / d \mathrm{CI})>0$ and at the same $(d \mathrm{U} / d \mathrm{CI}) \geq 0$; and proposes a positive economic relation between growth in the creative industries and growth in the aggregate economy. Based on the results of our research, we can conclude that according to the premises of the second model, the second model is predicting the relationship between the growth in the creative industries and in the 
aggregate economy in Slovakia. In years 2011 and 2015, $d \mathrm{U} / d \mathrm{CI}$ was almost the null, so we count it as the null for our purpose. The limitation of this research is in the missing data from few years.

\section{Conclusion}

Policymakers must acknowledge the conceptual and empirical challenges in defining and measuring the creative economy. Analysts should reflect on the different approaches that have been adopted in different studies and develop a clear understanding of why transparent definition and measurement is important for policy-making purposes. There is no better way to engage with the issues than looking at some data.

The first model mentioned in the paper was not confirmed and it is not valid in Slovakia. The second model linked to the growth of the creative industries and the rest of the economy is predicting the dynamic behaviour of the creative industries' entities. Yet in both cases, policy should properly treat the creative industries as a 'special sector' $[14,15]$. This is not because it is economically significant, but because it powers the growth of other sectors. This may plausibly lead to intervention, but unlike model 1 , the ostensible purpose of this is to invest in economic growth, or to invest in the development of capacity to meet growth in demand.

There are several issues open for further research. Firstly, some dimensions of culture that could be included are at present not included in the model 1 and 2, such as existing legislation in culture. Finally, the analysis should be broader in terms of time dimension and accuracy of data, but we are unfortunately limited in this aspect with existing cultural statistical data. With improved cultural statistics, also a more developed and theoretically better founded analysis would be possible. We therefore see our article primarily as a much-needed step towards developing statistical tools in empirical cultural policy on a consistent basis, hoping to stimulate research, including the verification of our findings.

This paper is the output of the scientific grant VEGA n. 1/0340/19 "The Entrepreneurial Dimension of Creative industries in the Context of Innovation and Smart Growth" $(50 \%)$ and the internal grant project of the University of Economics in Bratislava (Faculty of Business Management) no. I-20-10100 called "Research of Creative Industry Enterprises with regard to Their Life Cycle in the Slovak Republic" (50\%).

\section{References}

1. D. Rybárová, Creative Industry as a Key Creative Component of the Slovak Economy. In Globalization and its Socio-Economic Consequences 2019 (Rajecké Teplice, Slovakia, 1-8, 2019)

2. A. Srakar, V. Čopič, M. Verbič, European cultural statistics in a comparative perspective: index of economic and social condition of culture for the EU countries. Journal of Econometrics, 42, 163-199 (2018)

3. S. Šagátová, The Impact of globalization on the development of creative industries businesses. In Globalization and its Socio-Economic Consequences 2019 (Rajecké Teplice, Slovakia, 1-8, 2019)

4. M. Bertanha, Regression discontinuity design with many thresholds. Journal of Econometrics, 218, 216-241 (2020)

5. L. Bauwens, E. Otranto, Nonlinearities and regimes in conditional correlations with different dynamics. Journal of Econometrics, 217, 496-522 (2019)

6. S. Cerisola, Creativity and local economic development: the role of synergy among different talents. Papers in Regional Science, 97, 199 - 209 (2018) 
7. A. Lemmetyinen, Entrepreneurship in culture and creative industries: perspectives from companies and regions. International Small Business Journal-Researching Entrepreneurship, 37, 417-418 (2019)

8. Y. Wijngaarden, E. Hitters, P.V. Bhansing, 'Innovation is a dirty word': contesting innovation in the creative industries. International Journal of Cultural Policy, 25, 392-405 (2019)

9. W. Yu, Creative industries agglomeration and entrepreneurship in China: necessity or opportunity? Industry and Innovation, 27, 420-443 (2020)

10. XQ. Li, D. Gagliardi, I. Miles, Innovation in R\&D service firms: evidence from the UK. Technology Analysis \& Strategic Management, 31, 732-748 (2019)

11. E. Belfiore, Whose cultural value? Representation, power and creative industries. International Journal of Cultural Policy, 26, 383-397 (2020)

12. Eurostat, (2020, 24 March). GDP and main components (output, expenditure and income). Retrieved

from https://appsso.eurostat.ec.europa.eu/nui/show.do?dataset=nama_10_gdp\&lang=en.

13. Eurostat, (2020, $24 \mathrm{March})$. Value added and turnover of enterprises in the cultural sectors by NACE Rev. 2 activity. Retrieved from https://appsso.eurostat.ec.europa.eu/nui/submitViewTableAction.do.

14. F. Angelini, M. Castellani, Cultural and economic value: a critical review. Journal of Cultural Economics, 43, 173-188 (2019)

15. R. Boix, B. De-Miguel-Molina, J. L. Hervas-Oliver, Creative service business and regional performance: evidence for the European regions. Service Business, 7, 381 - 398 (2013) 